\title{
First report of Lasiodiplodia theobromae on Macadamia integrifolia in Brazil
}

\author{
Ivan Herman Fischer ${ }^{1}$, Marcos José Perdona ${ }^{1}$, Juliana Cristina Sodário Cruz ${ }^{1}$, Ana Carolina Firmino ${ }^{2}$
}

${ }^{1}$ Polo Regional Centro Oeste, Av. Rodrigues Alves, 40-40, CEP - 15678-000, Bauru, SP. ${ }^{2}$ UNESP/FCAT/Campus Dracena, Rod. Comandante João Ribeiro de Barros, Km 651 - Das Antas, CEP - 17900-000, Dracena, SP

Corresponding author: Ivan Herman Fischer (ihfische@apta.sp.gov.br)

Data de chegada: 21/09/2016. Aceito para publicação em: 14/02/2017.

$10.1590 / 0100-5405 / 169154$

Macadamia tree (Macadamia integrifolia Maiden \& Betche) is a plant native to the rainforests of Australia. Its nut is rich in monounsaturated oils and is considered an excellent energy source. In August 2013, samples of branches and bark of the trunk of macadamia plants were received for laboratory analysis; they were from an eightyear-old commercial orchard located in São João da Boa Vista, São Paulo State, Brazil, and presented symptoms of sunken canker on the bark (Figure 1A), while some plants had gum exudations, which culminated in dry terminal branches. At least 10 plants of the orchard were symptomatic. Fragments of diseased bark were previously surface-sterilized by immersion in $70 \%$ ethanol for $30 \mathrm{~s}$ and $1 \%$ sodium hypochlorite for $30 \mathrm{~s}$, and then washed in sterile distilled water. Small sections ( $0.5 \mathrm{~cm}$ long) were cut from the edge of an advancing lesion on the diseased bark and placed directly on water agar medium. The developed fungal colonies were placed on potato dextrose agar (PDA) medium and, subsequently, identified based on morphologic characters. Formed cultures were dark grey colored after seven days. Pycnidia were stromatic, globose and ostiolate. Conidia were initially hyaline, 1-celled and subovoid. When mature, conidia were 1-septate, brown and measured 26-31 x 12-16 $\mu \mathrm{m}$, typical of Lasiodiplodia theobromae (Pat.) Griff. \& Maubl. Presence of Botryosphaeria rhodina (Berk. \& M.A. Curtis) (teleomorph of L. theobromae) was not detected in the bark with canker or in the culture medium. ITS1 and ITS4 sequenced region of the isolate showed $98 \%$ similarity to the isolate of $L$. theobromae (AY585345). Pathogenicity test was performed for three isolates through attachment with adhesive tape of PDA plugs containing mycelium of the fungus on the shoot in five healthy plants of macadamia aged four months. Plants were maintained in a humid chamber for the first $24 \mathrm{~h}$ after inoculation and conditioned in a greenhouse. After seven days of inoculation, necrosis on the shoot was observed (Figure 1B). Pathogenicity was confirmed by recovering inoculated isolates from infected tissues. In Australia, Lasiodiplodia sp. was reported causing husk rot of macadamia (Mayers, P.E. Epidemiology and control of husk spot of macadamia. Australian Macadamia Society News Bulletin, v.25, p.59-64, 1998). This is the first record of L. theobromae causing disease to macadamia plants in Brazil.
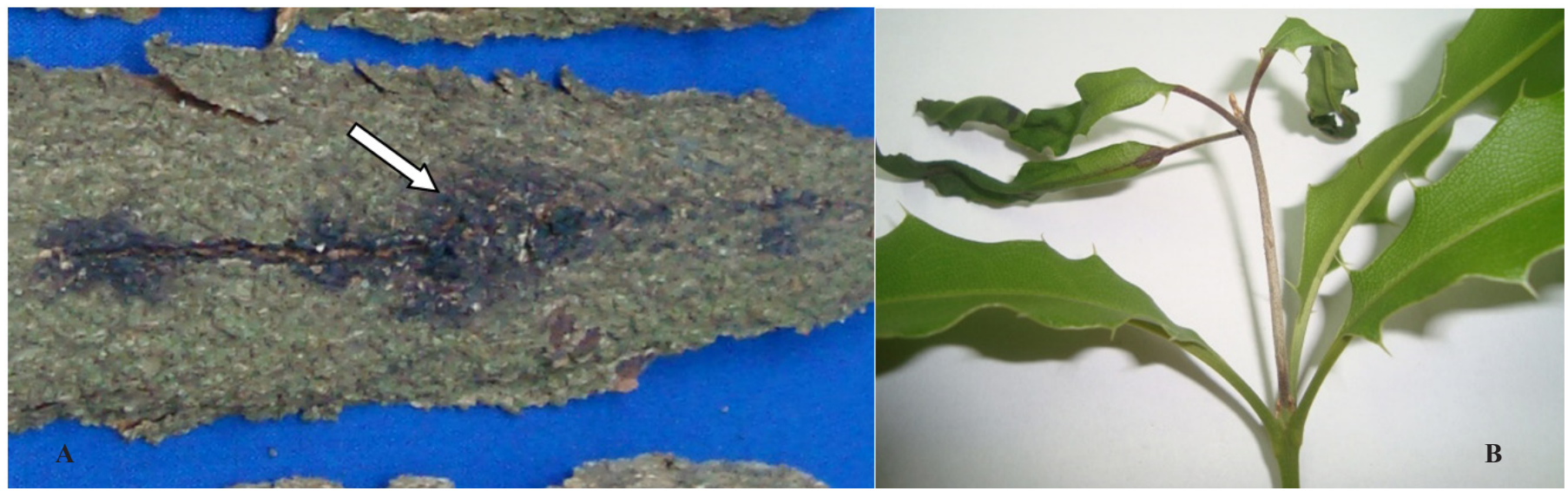

Figure 1.A. Macadamia branch bark removed from the trunk with symptoms of canker of Lasiodiplodia theobromae; B. Necrosis on the macadamia shoot after seven days of the inoculation of L. theobromae 